\title{
Prevalence and Prognostic Significance of Neuroendocrine Cells in Esophageal Adenocarcinoma
}

\author{
Katherine Hamilton, M.D., Alberto Chiappori, M.D., Sandy Olson, M.S., John Sawyers, M.D., \\ David Johnson, M.D., Kay Washington, M.D., Ph.D. \\ Department of Pathology, Nashville Veterans Affairs Medical Center (KH); Departments of Pathology, \\ Medicine (AC, DJ), and Surgery (JS), Vanderbilt University Medical Center; and Vanderbilt-Ingram Cancer \\ Center (SO, KW), Nashville, Tennessee
}

Neuroendocrine differentiation is common in adenocarcinomas of the stomach and colon and may be associated with a slightly better prognosis in gastric adenocarcinoma. We studied neuroendocrine differentiation in esophageal adenocarcinomas and associated Barrett's esophagus (BE) to determine association with patient outcome. Fifty-eight cases of esophageal adenocarcinoma (15 biopsies, 43 resections) from 52 patients were stained with a monoclonal antibody to chromogranin (CG). Medical records were reviewed for tumor stage, response to therapy, and patient survival. Thirty-two patients received radiation and chemotherapy, and four received radiation. Twelve of $58(20.7 \%)$ esophageal adenocarcinomas contained scattered CG-positive cells. Tumors with CG-positive cells were moderately to poorly differentiated, and many consisted of large cribriform glands, similar to intestinal-type adenocarcinomas. One case of small cell carcinoma of the esophagus was weakly CG positive; another was negative. Neuroendocrine differentiation was retained in lymph node metastases in two cases but lost in three other cases. In 10 CG-negative primary tumors, lymph node metastases were also negative. For five of six patients with paired biopsy/resection specimens, no CG-positive cells were seen in either specimen; one patient had CG-positive cells only in the resection. There was no difference in tumor stage at surgery or survival time between CGpositive and CG-negative tumors. $B E$ was present in 34 cases and contained CG-positive cells in 21 of 34 (61.8\%). Low-grade dysplasia contained CG-positive cells in 11 of 14 cases (78.6\%) and high-grade dys-

Copyright () 2000 by The United States and Canadian Academy of Pathology, Inc.

VOL. 13, NO. 5, P. 475, 2000 Printed in the U.S.A.

Date of acceptance: October 26, 1999.

This project was supported in part by a Cancer Center grant from the National Cancer Institute (CA 68485).

Address reprint requests to: Kay Washington, M.D., Ph.D., C-3321 MCN, Department of Pathology, Vanderbilt University Medical Center, Nashville, TN 37232; e-mail: kay.washington@mcmail.vanderbilt.edu; fax: 615343-7023. plasia in 3 of 6 cases. Fourteen of $21(66.7 \%)$ adenocarcinomas associated with CG-positive BE were negative for CG. In summary, neuroendocrine differentiation is common in $\mathrm{BE}$ and is retained in lowand high-grade dysplasia but is usually lost in esophageal adenocarcinoma. The presence of scattered neuroendocrine cells does not affect patient outcome.

KEY WORDS: Adenocarcinoma, Barrett's esophagus, Chromogranin, Esophageal neoplasms, Neuroendocrine.

Mod Pathol 2000;13(5):475-481

Neuroendocrine differentiation in gastrointestinal (GI) neoplasms may occur in one of several patterns. Most GI tumors with diffuse neuroendocrine differentiation can be classified as carcinoids, neuroendocrine carcinomas, or small cell undifferentiated carcinomas. Tumors with mixed phenotype can usually be classified as mixed tumors, which contain both adenocarcinoma and neuroendocrine cells, intimately intermixed; "collision" tumors, with localized areas of carcinoid or neuroendocrine carcinoma abutting an adenocarcinoma or adenoma; and amphicrine tumors, rare tumors showing neuroendocrine and glandular differentiation within the same cell. Probably the most common pattern of neuroendocrine differentiation in GI neoplasms, however, is the presence of scattered tumor cells showing neuroendocrine differentiation in an otherwise typical adenocarcinoma. The presence of neuroendocrine cells in colonic adenocarcinomas (1-5) and gastric adenocarcinomas (6) has long been recognized. Although up to $42 \%$ of typical colon adenocarcinomas contain scattered chromogranin (CG)-positive cells (4), this finding does not seem to influence prognosis, and these tumors are not classified as mixed adenocarcinoma/ neuroendocrine tumors. In contrast, gastric adenocarcinomas with neuroendocrine differentiation may be associated with a slightly better prognosis than those without neuroendocrine features (6). 
Neuroendocrine cells have been described in the metaplastic mucosa of Barrett's esophagus (BE) and in esophageal carcinomas. Studies have shown that 65 to $90 \%$ of cases with BE and approximately $30 \%$ of adenocarcinomas of the lower esophagus contain argyrophil cells $(7,8)$. In addition, cases of esophageal small cell carcinoma (9) and carcinoid in the presence of an adenocarcinoma (10) have been described. However, the significance of neuroendocrine differentiation in esophageal adenocarcinomas has not been studied.

Because of the possibility that neuroendocrine differentiation in adenocarcinomas of the GI tract, especially those of the upper GI tract, may affect prognosis in a site-specific manner, we examined the prevalence and pattern of CG expression in esophageal adenocarcinomas and the effect of neuroendocrine differentiation on patient survival.

\section{MATERIALS AND METHODS}

\section{Case Selection}

Fifty-eight cases of esophageal adenocarcinoma (15 biopsies, 43 resections) from 52 patients were retrieved from the files of Vanderbilt University Medical Center and the Nashville Veterans Affairs Medical Center. Hematoxylin and eosin-stained sections from routinely processed formalin-fixed, paraffin-embedded tissues were examined for each case. Squamous cell carcinoma cases were excluded, as were cases judged to be of gastric primary (i.e., when the bulk of the tumor was in the subcardiac stomach). Paired biopsy/resection specimens containing adenocarcinoma were available for six patients, all of whom had received preoperative chemoradiation. Of the 43 resection specimens, 26 were from patients who had received preoperative chemoradiation, 3 were from patients who had received preoperative radiation only, 1 was from the patient who underwent thermal ablation, and 13 were from patients who did not receive preoperative therapy. Of the nine patients whose biopsies but not resection specimens were available for study, one had no postbiopsy therapy at Vanderbilt or the Nashville VA, seven underwent chemoradiation or radiation without subsequent resection (three patients) or had resection specimens negative for carcinoma (four patients), and information concerning postbiopsy therapy was not available for one patient. Thus, a total of 32 patients were treated with radiation and chemotherapy, 4 received radiation alone, and 1 received thermal ablative therapy. Fourteen received no postbiopsy chemotherapy or radiation.

BE was defined as columnar epithelium containing goblet cells in the tubular esophagus. Dysplasia was diagnosed and graded according to published criteria (11). The adenocarcinomas were graded as well, moderately, or poorly differentiated, and the tumor pattern was also classified as large gland, medium gland, small gland, solid sheets or nests, and single cells, according to the predominant pattern. Two cases of poorly differentiated carcinoma were best classified as small cell neuroendocrine carcinoma. Lymph node metastases were examined in 14 cases.

\section{Immunohistochemical Staining and Interpretation}

Four-micron-thick sections of paraffin-embedded, formalin-fixed tissues were stained for CG A using the monoclonal antibody DAK-A3 (Dako, Carpinteria, CA) at 1:100 dilution. Adenocarcinomas and Barrett's mucosa were evaluated for cytoplasmic CG positivity and were scored on a scale of 0 to 3 , according to the number of positively staining cells, with $3+$ having strong cytoplasmic staining in most cells $(>50 \%), 2+$ having strong cytoplasmic staining in many cells (10 to $50 \%), 1+$ showing patchy staining $(<10 \%$ of cells) with reduced intensity, and 0 with no staining or trace staining only. The basally located polypeptidesecreting cells in adjacent gastric mucosa served as internal positive controls.

\section{Clinical Information and Statistical Analysis}

Medical records for each patient were reviewed for tumor stage, pre- or postoperative therapy, time to recurrence, and survival. The staging system used by the American Joint Committee on Cancer (12) was used for assigning clinical stage. Staging was based on the presence of viable tumor cells in the resected esophagus specimen, after preoperative therapy, and was not based on preoperative clinical staging. Survival was compared using Kaplan-Meier estimates.

\section{RESULTS}

\section{Barrett's Esophagus}

Thirty-four of 58 cases contained areas of BE (Table 1). In 21 of these cases, the Barrett's mucosa contained CG-positive cells, most numerous at the

TABLE 1. Expression of Chromogranin in Barrett's Esophagus

\begin{tabular}{lcc}
\hline \multicolumn{1}{c}{ Dysplasia } & Total Cases & Chromogranin-Positive BE \\
\hline No dysplasia & 13 & $6 / 13(46.2 \%)$ \\
Nondysplastic mucosa, in cases & 13 & $9 / 13(69.2 \%)$ \\
$\quad$ with dysplasia elsewhere & & \\
Low grade & 14 & $11 / 14(78.6 \%)$ \\
High grade & 6 & $3 / 6(50.0 \%)$ \\
Intramucosal carcinoma & 6 & $1 / 6(16.7 \%)$ \\
Total cases of $\mathrm{BE}^{a}$ & 34 & $21 / 34(61.8 \%)$ \\
\hline
\end{tabular}

BE, Barrett's esophagus.

${ }^{a}$ Some cases contained more than one grade of dysplasia. 
base of crypts, and sometimes occurring in small clusters (Fig. 1A). CG-positive cells located near the basement membrane (Fig. 1B) showed abluminally oriented positive granular staining. In some cases, generally in dysplastic mucosa, the CG-positive cells were located higher in the crypt, in the middle portion of the mucosa, in a pattern similar to neuroendocrine hyperplasia sometimes seen in gastric mucosa, and were not confined to the base of the crypt (Fig. 2). CG-positive cells were most often found in low-grade dysplasia and nondysplastic Barrett's mucosa in specimens with dysplasia elsewhere. All cases with both low-grade dysplasia and nondysplastic Barrett's mucosa showed concordance for CG positivity in dysplastic and nondysplastic mucosa. However, CG positivity was lost in three cases of high-grade dysplasia in which lowgrade dysplasia or nondysplastic mucosa contained CG-positive cells (Fig. 3).

In 13 cases with CG-negative Barrett's mucosa, only one associated adenocarcinoma $(7.7 \%)$ contained CG-positive tumor cells. In 21 cases with CG-positive Barrett's mucosa, 7 (33.3\%) adenocarcinomas contained CG-positive cells; in other words, CG expression was lost in two thirds of invasive tumors arising in the setting of BE containing
CG-positive cells. In 15 of 27 (55.6\%) cases with CG-negative tumors and associated BE, the Barrett's mucosa contained CG-positive cells. The majority of the CG-positive adenocarcinomas (7 of 11 cases [63.6\%]) were associated with Barrett's mucosa in the resection or biopsy specimen.

\section{Esophageal Adenocarcinoma}

Twelve of 58 cases of esophageal adenocarcinoma expressed CG (Table 2), with CG-positive cells scattered throughout the tumors. Nine tumors were scored as $1+$ and three as $2+$. Most CGpositive tumor cells were located at the periphery of neoplastic glands, away from the luminal surface. Expression of CG was not related to tumor grade. One of two cases of small cell carcinomas was weakly CG positive. All growth patterns were seen in the CG-positive cases, although the large gland pattern (Fig. 4), morphologically similar to colonic adenocarcinoma, was most common (five cases). In four cases, the predominant growth pattern was small to medium glands, and in four other cases, solid nests and single cells. The only tumor with $3+$ staining, not included in the total number of CGpositive cases, was an unusual microscopic carci-
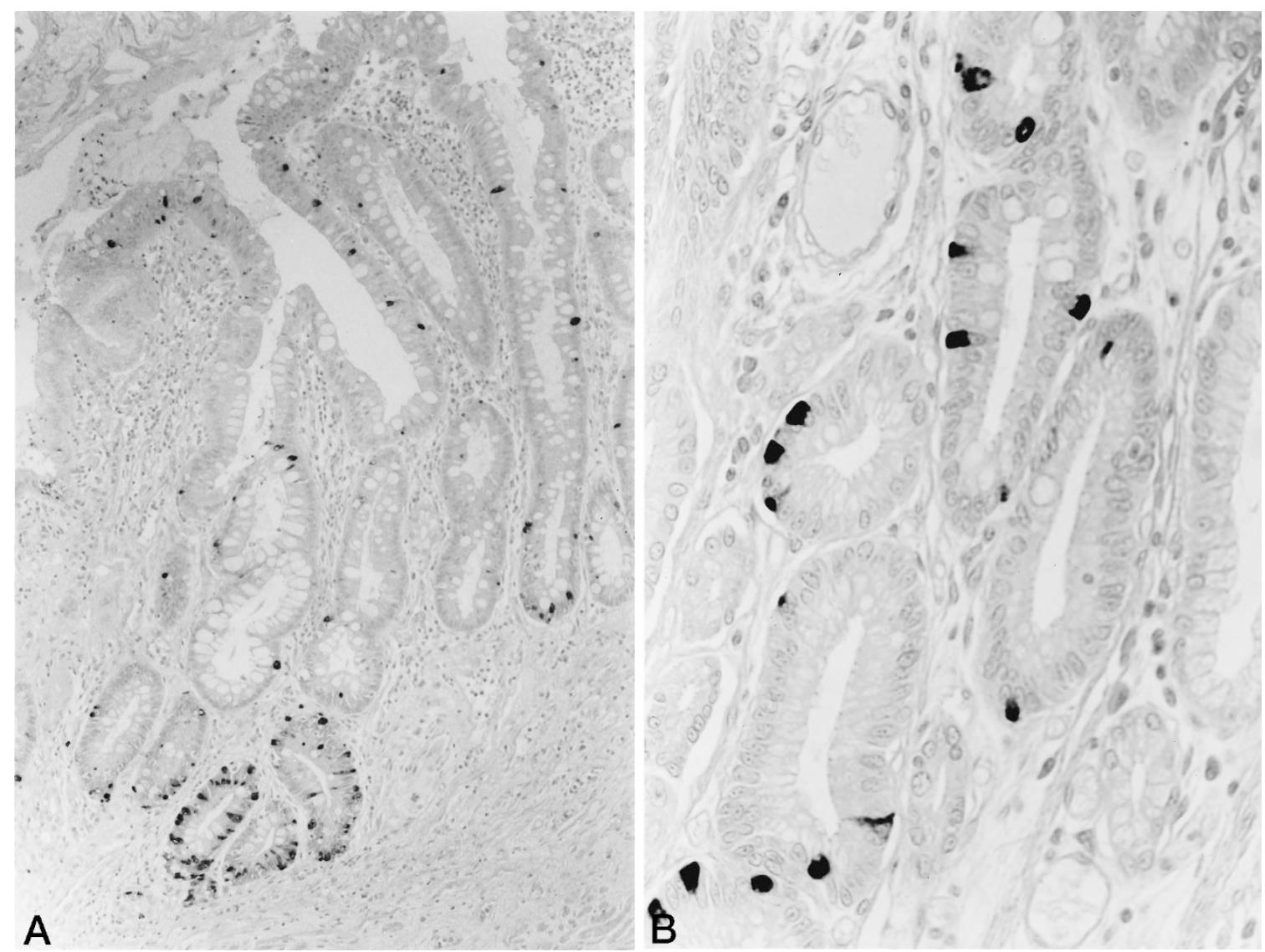

FIGURE 1. A, scattered chromogranin-positive cells, most numerous at the base of crypts, are present in Barrett's epithelium in this case. B, the chromogranin-positive cells in Barrett's mucosa are basally located, with abluminal positive staining, similar to the usual location of neuroendocrine cells in normal intestinal mucosa. 


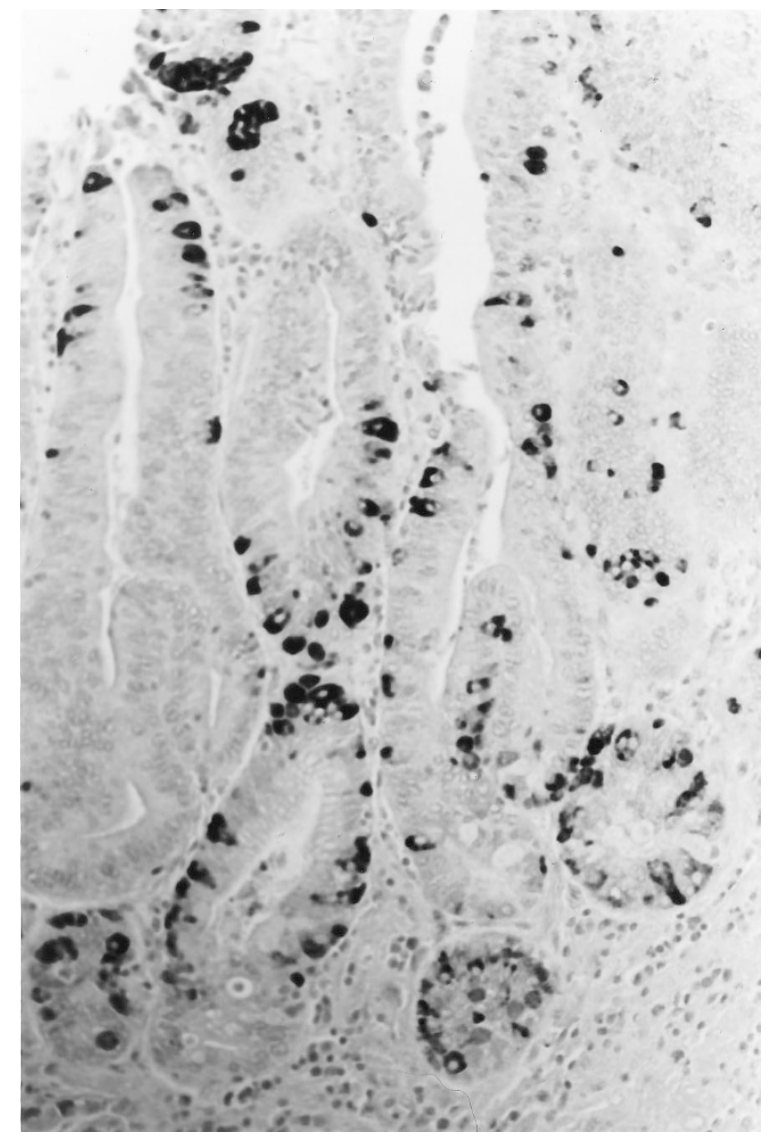

FIGURE 2. In this example of Barrett's esophagus with high-grade dysplasia, chromogranin-positive cells are more numerous than in nondysplastic mucosa, are present in clusters, and occur high up the crypt axis.

noid tumor (Fig. 5) arising in Barrett's mucosa in a resected esophagus with a poorly differentiated adenocarcinoma. This small carcinoid was separate from the main tumor, which was CG negative. The carcinoid was well differentiated and similar in morphology to small carcinoids arising in the stomach, and arose in an area of Barrett's mucosa containing numerous neuroendocrine cells. The carcinoid infiltrated the muscularis mucosae and involved the esophageal submucosa but did not extend into the muscularis propria.

Of the 14 cases with lymph node metastases, 5 had CG-positive primary tumors; CG staining was retained in the lymph node metastases in 2 of these cases (Fig. 4).

Paired biopsy specimens and resection specimens with residual adenocarcinoma were available for six patients, all of whom had received preoperative radiation and chemotherapy. For five of six patients, no CG-positive cells were seen in either specimen; one patient had CG-positive cells only in the resection. When the 43 resection specimens were separated by preoperative therapy, a similar percentage of specimens from patients who had received preoperative chemoradiation and those

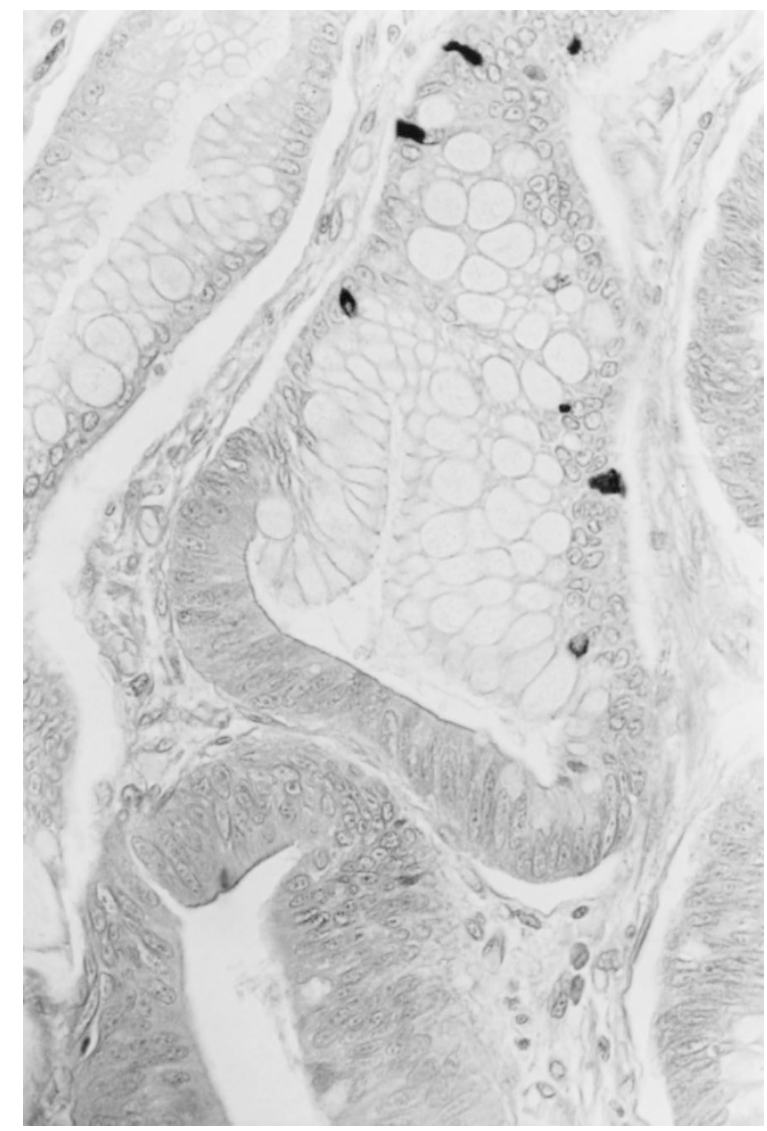

FIGURE 3. Nondysplastic Barrett's mucosa in this case contains scattered chromogranin-positive cells; adjacent dysplasia is negative.

who had not received preoperative therapy showed $1+$ and $2+$ positivity for CG (Table 3 ).

Although tumors with scattered CG-positive cells were more likely to be Stage III at resection (Table 2 ), this finding was not statistically significant and thus the presence of CG-positive tumor cells was not significantly related to tumor stage. When the tumors were examined using Kaplan-Meier estimates, the presence of CG-positive tumor cells was not significantly related to patient survival.

\section{Clinical Features}

Forty-nine of the patients were male, and 3 were female. Mean age was 62 years (median, 62.5 years; range, 37 to 92 years). All tumors examined arose in the distal esophagus. Seven tumors were classified as Stage I, 12 as Stage IIA, 7 as Stage IIB, 13 as Stage III, and 11 as Stage IV. Staging information was not available for two patients who had been treated with preoperative radiation and chemotherapy but who did not undergo surgery. One patient whose biopsy was included in the study had a complete pathologic response to preoperative chemoradiation (Stage $0)$. Neither of the two patients with small cell neuroendocrine carcinoma received preoperative 


\begin{tabular}{|c|c|c|c|}
\hline Cases $(n ; \%)$ & Tumor Grade $(n ; \%)$ & Stage $(n ; \%)$ & $\begin{array}{l}\text { Survival } \\
\text { (mo) }\end{array}$ \\
\hline CG positive $(12 / 58 ; 20.7)$ & $\begin{array}{l}\text { Well }(0 / 12 ; 0) \\
\text { Moderate }(5 / 12 ; 41.7) \\
\text { Poor }(7 / 12 ; 58.3)\end{array}$ & $\begin{array}{l}\text { I }(1 / 12 ; 8.3) \\
\text { IIA }(2 / 12 ; 16.7) \\
\text { IIB }(3 / 12 ; 25.0) \\
\text { III }(5 / 12 ; 41.7) \\
\text { IV }(1 / 12 ; 8.3)\end{array}$ & $\begin{array}{l}23.1 \text { (mean) } \\
9 \text { (median) }\end{array}$ \\
\hline CG negative $(46 / 58 ; 79.3)$ & $\begin{array}{l}\text { Well }(4 / 46 ; 8.7) \\
\text { Moderate }(17 / 46 ; 37.0) \\
\text { Poor }(25 / 46 ; 54.3)\end{array}$ & $\begin{array}{l}\text { I }\left(6 / 38 ;{ }^{a} 15.8\right) \\
\text { IIA }(10 / 38 ; 26.3) \\
\text { IIB }(4 / 38 ; 10.5) \\
\text { III }(8 / 38 ; 21.1) \\
\text { IV }(10 / 38 ; 26.3)\end{array}$ & $\begin{array}{l}19.6 \text { (mean) } \\
13 \text { (median) }\end{array}$ \\
\hline
\end{tabular}

CG, chromogranin.

${ }^{a} 38$ refers to number of patients, not cases. Staging information was not available for two patients; one patient whose biopsy was CG negative had no residual invasive carcinoma in the resection specimen (Stage 0).

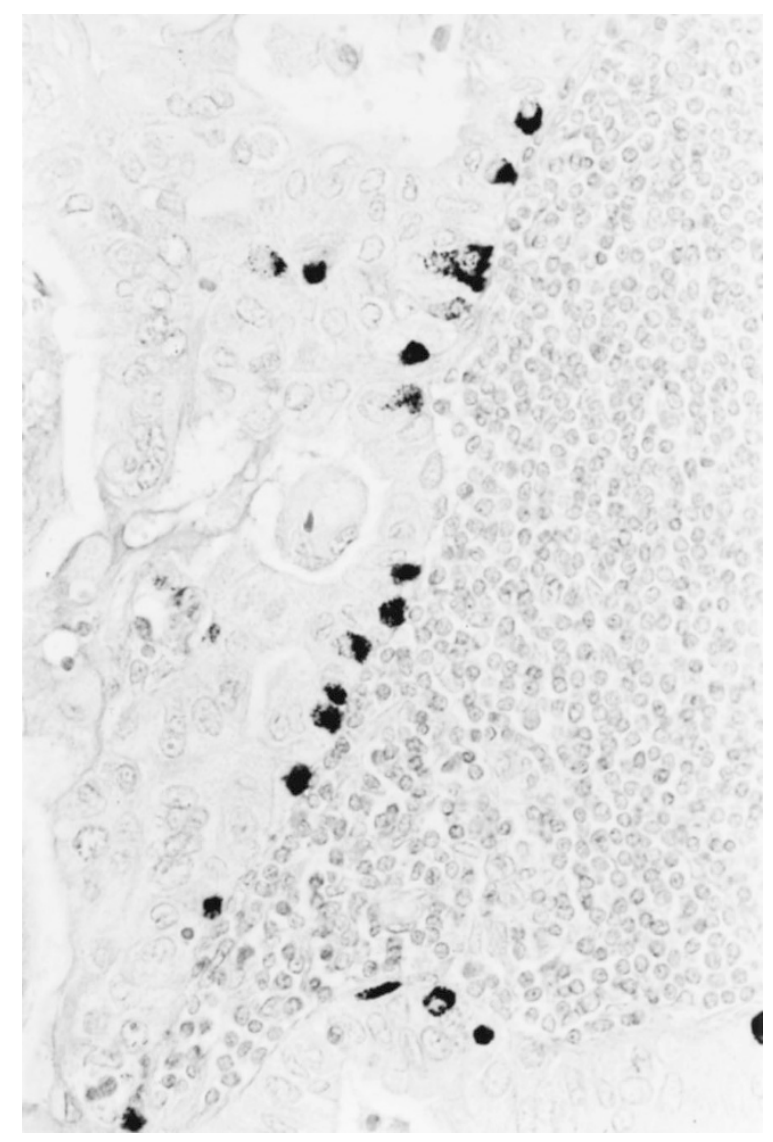

FIGURE 4. In the gland-forming adenocarcinomas that were chromogranin-positive, the positive tumor cells displayed abluminal staining. In this case, metastatic carcinoma in a lymph node (shown) and the primary tumor both contained chromogranin-positive cells.

chemoradiation; both patients were classified as having Stage III disease, and survival after surgery was 4 and 9 months.

\section{DISCUSSION}

A subset of GI adenocarcinomas and poorly differentiated carcinomas express CG, indicative of differentiation along neuroendocrine lines, and it seems that the significance of this neuroendocrine

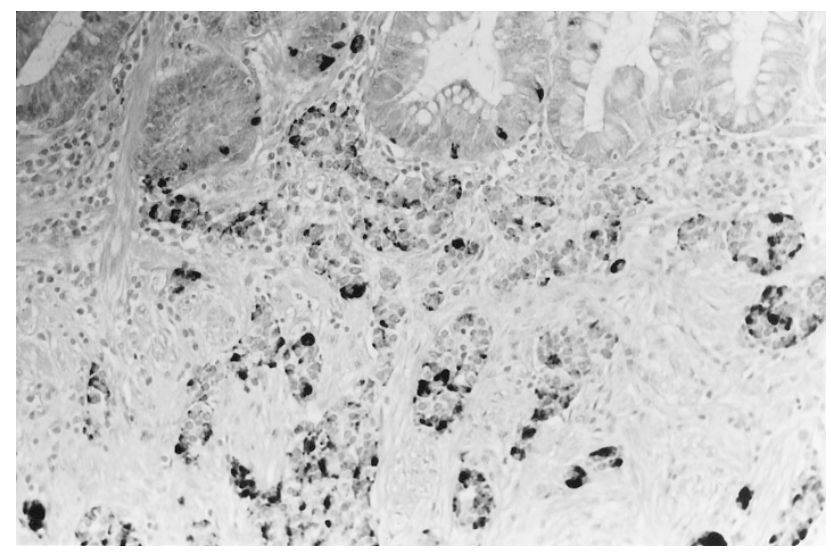

FIGURE 5. This incidental microscopic carcinoid tumor arising in Barrett's esophagus is strongly positive for chromogranin. A poorly differentiated adenocarcinoma elsewhere in the specimen was negative for chromogranin.

differentiation in GI tumors is pattern and site dependent. For instance, poorly differentiated carcinomas of the colon with diffuse neuroendocrine differentiation exhibit highly aggressive behavior analogous to that of small cell carcinoma of the lung, with widespread metastases at the time of diagnosis (13). In contrast, in gastric carcinomas, neuroendocrine differentiation may have a slightly better prognosis compared with typical gastric adenocarcinoma (6). Carcinomas that display diffuse neuroendocrine differentiation are relatively rare, however, compared with otherwise typical adenocarcinomas that contain scattered tumor cells showing neuroendocrine differentiation. Such adenocarcinomas of the colon have been the subject of several relatively large studies (1-5). Most of these studies found that the presence of these scattered tumor neuroendocrine cells had no detectable influence on stage or prognosis and no association with tumor grade (2-4). In other studies, the effect was of marginal statistical significance $(1,5)$, indicating that any effect of this pattern of neuroendocrine differentiation on clinical outcome is likely to be small at best. Although de Bruine and colleagues (5) suggested that patients who have Stage III car- 


\begin{tabular}{|c|c|c|c|c|}
\hline $\begin{array}{c}\text { Chromogranin } \\
\text { Positivity in Tumor }\end{array}$ & $\begin{array}{c}\text { No Preoperative } \\
\text { Treatment } \\
(n ; \%)\end{array}$ & $\begin{array}{c}\text { Preoperative } \\
\text { Chemoradiation } \\
(n ; \%)\end{array}$ & $\begin{array}{c}\text { Preoperative } \\
\text { Radiation } \\
(n ; \%)\end{array}$ & $\begin{array}{c}\text { Preoperative } \\
\text { Thermal Ablation }\end{array}$ \\
\hline 0 & $(11 / 13 ; 84.6)^{a}$ & $(20 / 26 ; 76.9)$ & $(2 / 3 ; 66.7)$ & $1 / 1$ \\
\hline $1+$ & $(1 / 13 ; 7.7)$ & $(4 / 26 ; 15.4)$ & $(1 / 3 ; 33.3)$ & 0 \\
\hline $2+$ & $(1 / 13 ; 7.7)$ & $(2 / 26 ; 7.7)$ & $(0 ; 0)$ & 0 \\
\hline
\end{tabular}

${ }^{a}$ One resection specimen contained adenocarcinoma (negative for chromogranin expression) and a microcarcinoid ( $3+$ chromogranin expression).

cinomas that contain numerous neuroendocrine cells might have a worse outcome, Foley et al. (4) reported that CG positivity did not correlate with disease-free or overall survival in 48 patients who had Stage III cancer. Although it is possible that a small subset of patients who have colonic adenocarcinoma that contains numerous neuroendocrine cells (defined as $>1+$ cell per square millimeter) may have a poorer prognosis, these patients are relatively uncommon and no significant conclusions can be drawn from the published data. In our study of esophageal adenocarcinomas, scattered CG-positive cells were relatively common, occurring in approximately $22 \%$ of cases, similar to the reported frequency in adenocarcinoma of the colon $(3,5)$. Similarly, in our study of esophageal adenocarcinomas, expression of CG was not related to tumor grade or stage, and the presence of CGpositive cells had no significant effect on patient survival.

In normal gastric and intestinal mucosa, CGpositive endocrine cells are located relatively deep in the mucosal crypts or glands, adjacent to the basement membrane. In esophageal adenocarcinomas, scattered CG-positive tumor cells generally were located at the periphery of neoplastic glands, away from luminal surfaces, in a position analogous to the basal location of CG-positive cells in nonneoplastic mucosa. This basal location was most evident in cases in which the adenocarcinoma resembled colonic or intestinal adenocarcinoma.

CG-positive cells were common in Barrett's mucosa and were located in the lower portion of the crypt, in a position analogous to neuroendocrine cells in normal GI mucosa. Neuroendocrine cells were most often found in low-grade dysplasia, where they were often particularly numerous, in a pattern similar to that seen in neuroendocrine cell hyperplasia in the stomach. In dysplastic Barrett's mucosa, the CG-positive cells often extended higher up the crypt axis than in nondysplastic mucosa. However, the presence or absence of neuroendocrine cells and their pattern of distribution cannot be used as a diagnostic criterion for dysplasia in BE, as CG-positive cells were present in nondysplastic and dysplastic mucosa. CG expression was less commonly present in higher grades of dysplasia and was lost in invasive adenocarcinoma in two thirds of cases. It was distinctly uncommon for an invasive adenocarcinoma to acquire neuroendocrine differentiation if the associated Barrett's mucosa did not contain neuroendocrine cells and was common for neuroendocrine differentiation to be lost in invasive adenocarcinoma. Most CG-positive esophageal adenocarcinomas arose in the setting of BE.

Some cases of esophageal adenocarcinoma respond dramatically to neoadjuvant radiation and chemotherapy, with no histologic evidence of viable tumor cells in the resected esophageal specimen (14). The tumor staging in this study was based on histologic evidence of tumor involvement and not on pretreatment clinical and radiologic staging data. Although some lymph nodes sampled contained areas of scar or xanthogranulomatous inflammation and may represent lymph nodes previously involved by metastatic carcinoma, these changes may also be due to previous infection or other causes of reactive lymphadenopathy, and those lymph nodes were considered negative. The effect that radiation and chemotherapy may have on CG expression in GI carcinomas is not known, and because of the limited numbers of paired biopsy-resection specimens, we are unable to draw any related conclusions from this study. However, comparison of resection specimens from patients who received no preoperative therapy and those who received preoperative chemoradiation showed no statistically significant difference in the prevalence of CG-positive tumor cells, providing indirect evidence that the presence of cells showing neuroendocrine differentiation in these tumors is affected only slightly, if at all, by treatment.

In summary, neuroendocrine cells are common in BE; the observed frequency with staining for CG $(61.8 \%)$ in this study is similar to that reported for argyrophil staining (65 to 90\%) $(7,8)$. Neuroendocrine differentiation is usually lost in the associated invasive adenocarcinoma, although scattered neuroendocrine tumor cells were found in low numbers in $20 \%$ of cases. The presence of scattered neuroendocrine cells had no discernible effect on patient outcome, although examination of CG expression in a larger series of cases is desirable to confirm this observation. 


\section{REFERENCES}

1. Hamada Y, Oishi A, Shoji T, Takada H, Yamamura M, Hioki $\mathrm{K}$, et al. Endocrine cells and prognosis in patients with colorectal carcinoma. Cancer 1992;69:2641-6.

2. Smith DM Jr, Haggitt RC. The prevalence and prognostic significance of argyrophil cells in colorectal carcinomas. Am J Surg Pathol 1984;8:123-8.

3. Mori M, Mimori K, Kamakura T, Adachi Y, Ikeda Y, Sugimachi K. Chromogranin-positive cells in colorectal carcinoma and transitional mucosa. J Clin Pathol 1995;48:754-8.

4. Foley EF, Gaffey MJ, Frierson HF Jr. The frequency and clinical significance of neuroendocrine cells within stage III adenocarcinomas of the colon. Arch Pathol Lab Med 1998; 122:912-4.

5. de Bruine AP, Wiggers T, Beek C, Volovics A, von Meyenfeldt $\mathrm{M}$, Arends JW, et al. Endocrine cells in colorectal adenocarcinomas: incidence, hormone profile and prognostic relevance. Int J Cancer 1993;54:765-71.

6. Rogers LW, Murphy RC. Gastric carcinoid and gastric carcinoma. Am J Surg Pathol 1979;3:195-202.

7. Jaskiewicz K, Louw J, Anichkov N. Barrett's oesophagus: mucin composition, neuroendocrine cells, p53 protein, cellular proliferation and differentiation. Anticancer Res 1994; 14:1907-12.
8. Griffin M, Sweeney EC. The relationship of endocrine cells, dysplasia and carcinoembryonic antigen in Barrett's mucosa to adenocarcinoma of the oesophagus. Histopathology 1987; 11:53-62.

9. Beyer KL, Marshall JB, Diaz-Arias AA, Loy TS. Primary smallcell carcinoma of the esophagus. J Clin Gastroenterol 1991; 13(2):135-41.

10. Cary NRB, Barron DJ, McGoldrick JP, Wells FC. Combined oesophageal adenocarcinoma and carcinoid in Barrett's oesophagitis: potential role of enterochromaffin-like cells in oesophageal malignancy. Thorax 1993;48:404-5.

11. Reid BJ, Haggitt RC, Rubin CE, Roth G, Surawicz CM, Van Belle G, et al. Observer variation in the diagnosis of dysplasia in Barrett's esophagus. Hum Pathol 1988;19(2):166-78.

12. American Joint Committee on Cancer. AJCC cancer staging handbook. 5th ed. Philadelphia: Lippincott-Raven, 1998.

13. Gaffey MJ, Mills SE, Lack EE. Neuroendocrine carcinoma of the colon and rectum: a clinicopathologic, ultrastructural, and immunohistochemical study of 24 cases. Am J Surg Pathol 1990;14:1010-23.

14. Stewart JR, Hoff SJ, Johnson DH, Murray MJ, Butler DR, Elkins CC, et al. Improved survival with neoadjuvant therapy and resection for adenocarcinoma of the esophagus. Ann Surg 1993;218:571-8.

\section{Book Review}

\section{Laskaris G: Color Atlas of Oral Disease in Chil- dren and Adolescents, New York, Thieme, 352 pp, 1999 (\$129).}

The strength of this text is the large number of excellent color images of oral and cutaneous diseases. There are 495 illustrations, most in color and of superb quality. Some are accompanied by pertinent radiographs, as well as photomicrographs. Unfortunately, for the surgical pathologist, the photomicrographs number fewer than 30 and are not of the same quality as the clinical photographs. In addition, many of the photomicrographs show only the classic features seen in all pathology texts and would be of limited value in making a diagnosis in controversial cases. A few classic immunofluorescence images of mucosal diseases are also included, but one is incorrectly labeled. Some diseases have accompanying written histopathologic descriptions, but these are very general and would be of limited value in difficult histopathologic diagnoses. Of the same general quality are short descriptions of etiology, clinical features, treatment, and differential diagnoses.
Topics in the atlas include developmental and reactive lesions, infections, systemic diseases, mucocutaneous diseases, and both benign and malignant tumors. It is curious that for an atlas of oral diseases, only a few odontogenic cysts and no odontogenic tumors are included. A comprehensive and current bibliography is included but is referenced only to chapters and not to specific diseases. This makes it difficult for the reader to find key references for the disease in question.

I do not recommend this atlas for surgical pathologists; however, I highly recommend the excellent clinical photographs of both common and rare diseases for dermatologists, otolaryngologists, pediatricians, and family practice physicians as well as for all those in dentistry who see pediatric patients. These images alone are worth the price of this text.

\author{
Bruce F. Barker \\ University of Missouri-Kansas City \\ School of Dentistry \\ Kansas City, Missouri
}

